\title{
Living in quiet desperation: The mental health epidemic in Australia's higher education
}

Health Education Journal

$1-14$

(C) The Author(s) 2019

Article reuse guidelines: sagepub.com/journals-permissions DOI: $10.1177 / 0017896919867438$ journals.sagepub.com/home/hej

@SAGE

\section{Wayne Usher}

School of Education and Professional Studies, Griffith University, Gold Coast, QLD, Australia

\begin{abstract}
Objective: This study sought to investigate the relationship between personal, university, home and community influences on Australia's university students' mental health status.

Design: Positioned within a qualitative, interpretivist paradigm, the study collected data from participants $(n=934)$ by means of an online survey requesting lived or witnessed experiences concerning mental health concerns. Bronfenbrenner's socio-ecological model informed the design of the study.

Setting: Five major Australian higher educational settings.

Method: Leximancer software was used for concept development. Data were analysed using thematic coding.

Results: Findings provide qualitative data of university students' experiences concerning mental health status, as measured across four domains. Themes identified include personal (stress, anxiety, life skills), university (grades/free physical activity) and home (closer to home, support networks) dimensions. There was no unprompted reference to the community domain. Results reinforce the need to ensure that current and future student mental health policies and initiatives are implemented within each of the domains addressed - to ensure a more holistic approach to students' well-being and care.

Conclusion: Findings highlight challenges concerning Australia's university students' mental health status. Findings present an opportunity for the university sector, community health services, and sports and fitness organisations to develop and implement future collaborative health promotion in higher education settings.
\end{abstract}

\section{Keywords}

Australia, health services, higher education, mental health, students

\section{Corresponding author:}

Wayne Usher, School of Education and Professional Studies, Griffith University, Gold Coast, QLD 4222 Australia. Email:w.usher@griffith.edu.au 


\section{Introduction}

Mental health concerns the ability of an individual to cope with the normal stresses of life and make a contribution to the community (Veness, 2016). A number of mental health issues (e.g. schizophrenia, depression, bipolar disorder and anxiety) may result in an individual's diminished capacity to coping with the ordinary demands of life (Stallman, 2010). Entry into higher education is typically characterised by a new level of independence for young people characterised by rapid, interrelated changes in body, mind and social relationships. Pullman et al. (2009) posit that university students' mental health status may be shaped both positively and negatively by this dynamic transitional period. As a result, increasing attention is being directed towards the design and implementation of services to support the mental health of university students.

A number of significant indicators, both psychologically and otherwise, warrant investigation throughout the higher education period and its impact on students' mental health. Of concern is the fact that university students are five times more likely to be diagnosed with a mental health issue (Stallman, 2010) compared to others, with a predicted \$16 trillion lost from the world's economy in the next 20 years as a direct or indirect result of poor mental health (Veness, 2016). Furthermore, students are less likely to perform well at university when suffering from poor mental health resulting in (1) lower educational achievement, (2) increased enrolment cancellations, (3) negative learning and teaching experiences and (4) more days out of role. Such a negative spiral can in turn lead to future personal problems including decreased employment, lower income and standard of living, and increased impairment (Australian Institute of Health and Welfare [AIHW], 2012). However, despite these findings, there exists limited contemporary data that can be used to inform best practice and future policy directions.

\section{A socio-ecological model}

Informed by Bronfenbrenner's $(1994,1999)$ socio-ecological systems model, this study sought to explore the factors that appear critical in helping or hindering a students' mental health status and how this, in turn, impacts their university experience. At its core, Bronfenbrenner's (1999) work suggests that an individual's development is strongly affected by layered interactions between an individual and their environment. By gaining an in-depth understanding of individuals' lived and/ or witnessed experiences, the multidimensional interconnections between a number of domains including the (1) the personal, (2) the home, (3) the university and (4) the community can be understood. Findings from this study identify the potential health-promoting nexus and patterns of associations between these four socio-ecological domains as they impact the lives of Australia's university students and affect their mental health status.

\section{Methods}

\section{Approach}

This study aimed to investigate Australia's university students' lived or witnessed experiences, seeking to add to understanding of mental health issues in Australian higher education. The study took place within an interpretive paradigm which influenced how the data were collected, analysed, interpreted and presented. Interpretive research seeks to study social reality from the 'inside', using open-ended methods of data collection and employing a flexible research design (Modernes, 2007). Importantly, it emphasises that the results of this study will rarely uncover a single interpretive 'truth'. Instead, there exist multiple interpretive communities each with their own criteria for evaluating what is discovered. As Denzin and Lincoln (1998) put it, 
The sets of answers given are in all cases human constructions; that is, they are all inventions of the human mind and hence subject to human error. No construction is or can be incontrovertibly right; advocates of any particular construction must rely on persuasiveness and utility rather than proof in arguing their position. (p. 37)

In this study, qualitative data were collected by means of an online survey platform and was inductively analysed to identify recurrent patterns or common themes using Bronfenbrenner's model that served as an interpretive theoretical lens. By aiming to understand the perspectives of participants, the researcher acted as what Imel et al. (2002) describe as a 'filter for meaning', shedding light on issues associated with mental health and providing potential recommendations to support students experiencing mental health and emotional well-being problems.

\section{Participants}

Participants $(n=934)$ came from five major Australian universities and data were collected over a 5-month period. As part of the ethics approval granted by Griffith University (GU Ref No: $\mathrm{EDN} / 56 / 15 / \mathrm{HREC}$ ), participating universities were informed that no institution would be identified. All data were therefore de-identified in this research.

Given the nature of the topic under investigation, it was felt more appropriate to have students provide anonymous responses rather than do so through face-to-face or group interaction. Participants were therefore invited by email to complete an anonymous online survey.

There were no specific selection criteria other than participants needing to be either a full- or part-time student and attending, at the time of the survey, one of the five selected Australian universities. All students in each university were asked to participate, irrespective of gender, nationality, age, year level or degree (undergraduate or postgraduate).

\section{Survey design}

The online survey provided participants with a number of open-ended questions, which provided the opportunity to comment on their lived or witnessed experiences of mental health issues within their university setting. Participants were not prompted to provide commentaries addressing the four study domains (personal, home, community, university), but rather to address the overall research goal. This was done intentionally so as to avoid the researcher influencing participants' responses. The approach generated rich and detailed responses.

Ten open-ended, online questions were provided to participants. Each required participants to reflect as to their first experience concerning mental health in higher education. Typical questions included, 'What is your experience (either lived or witnessed) concerning mental health issues in higher education?' and 'What [factors] do you think are impacting on students' mental health?' Further questions explored possible recommendations for addressing mental health among university students, such as, 'What recommendation/s could you make to assist/prevent students suffering from mental health issues?'

\section{Data analysis}

The analysis was informed by Creswell's (2008) Visual Model of the Coding Process in Qualitative Research. It involved what Creswell (2008) describes as the 'hand analysis of qualitative data' (p. 246). That is, data obtained from participants' online comments were read, marked up by hand and divided into parts 'to form descriptions and broad themes' (p. 251) relevant to the overarching 
research aim: namely, the relationships between personal, university, home and community domains in their impact on students' mental health.

Participants' responses were coded using an inductive approach so as to allow for themes to emerge, without trying to fit the data into a pre-established coding frame or the researcher's assumptions (Braun and Clarke, 2006). Inductive reasoning allowed the move from specific lived and/or witnessed experiences to broader generalisations and theories. The use of an inductive approach allowed for a rich and detailed thematic analysis that was able to capture unique aspects of the data in relation to the overall research aims.

Creswell's (2008) decoding processes coupled with the use of Leximancer software enabled the development of concepts and the cross-referencing of themes. Using both approaches, the collected data were analysed using a seven-step process:

1. Transcribing: transcripts were recorded verbatim and data were entered into Leximancer to develop a concept map.

2. Immersion: written transcripts were read and re-read to identify initial descriptive codes explore and organise the data.

3. Initial coding: descriptive codes were manually extracted and analysed for main central codes via a process of segmenting and labelling text.

4. Theme identification: central codes were then analysed for thematic codes and allocated to the appropriate descriptive code - in the form of descriptions and broad themes in the data.

5. Defining: thematic codes were elaborated upon and associated with appropriate central codes - specific themes were then linked to the concept map generated.

6. Reviewing: all the data were re-reviewed - themes were recorded, the above stages were repeated to ensure no loss of data and to eliminate any duplicate data - thereby reducing redundancy.

7. Refining: thematic codes were refined and defined through thematic sorting and checking.

Throughout the above process, Leximancer software was used to identify high-level concepts, visualising the key ideas and insights. Specifically, data presentation and analysis sought to link emergent themes and concepts to the four domains. Such a combined approach to data analysis procedures provided a systematic approach to recording, analysing and interpreting information and building a thematic profile of participants' experiences.

\section{Trustworthiness}

In research of this kind, trustworthiness is of paramount importance and is characterised by (1) credibility, (2) transferability, (3) dependability and (4) confirmability. To maximise trustworthiness, ongoing 'peer review' by experts (programme directors, senior colleagues, research statisticians and ethics committee members) took place prior to and during data collection. Credibility was worked towards by providing detailed processes to record, analyse and present commentaries, while transferability was heightened by implementing concise and rigorous methods for the collection and analysis of data, and describing the research context and the assumptions that were central to the research. To enhance dependability, an attempt was made to demonstrate that an honest picture of the phenomenon under scrutiny has been presented by detailing the nature and aim of the study, together with its implementation. Dependability was maximised by the use of peer and expert debriefing (as detailed above), which took place before and after data were collected and analysed. Finally, confirmability was worked towards by using an interpretive framework to ensure 
that data interpretation was not unduly affected by the researcher's personal point of view. The researcher also documented the procedures for checking and rechecking the data throughout this study, as outlined in the seven steps to data analysis.

\section{Positionality}

Since bias is a human characteristic, positionality in the context of inductive research requires consideration of the investigator's placement within the context of the study in question (England, 1994). While in this study the author, as a health education professional working with students in higher education, had a personal interest in exploring mental health in a university setting, there was little opportunity for him to directly influence the online responses provided. Such an approach allowed for the collection of good quality data. The careful collection and interpretation of data were assisted by the implementation of the aforementioned measures taken to heighten trustworthiness.

\section{Initial analysis}

Initial data coding, as set out by Creswell (2008), and Leximancer text analysis identified a number of common themes from participants' commentaries. These themes highlighted the impact of each of the four domains on mental health issues, both with respect to lived/witnessed experience and potential recommendations. Six main themes emerged which could be grouped as follows.

\section{Lived and witnessed experiences}

1. Personal - stressed and anxious

2. University - grades

3. Home-closer to home

\section{Recommendations}

1. Personal - life skills

2. University - free physical activity

3. Home - support networks

\section{Leximancer findings}

To support the Leximancer (Version 4.50.07) analysis of participants' comments $(N=983)$ related to experiences (lived or witnessed) of mental health issues among university students, responses were collated in a single Word file. Key and associated concepts linked to selected questions in the survey were identified. A key goal was to quantify the relationships between different concepts (i.e. the co-occurrence of concepts) and to represent this information in a ranked concept map (Figure 1) that could be used for exploring the content of the data. As illustrated, with $100 \%$ of concepts visible and with the thematic size set at 75\%, three major thematic concepts of issues, time and people were found to overlap.

As indicated in Table 1, participants were most likely to reflect (based on count relevance) on concepts such as issues, university, students, mental, anxiety, stress and people. They were least likely to reflect on concepts such as relationships, diagnosed, environment, lack and assessment. 
Table I. Ranked concepts.

\begin{tabular}{|c|c|c|c|c|c|}
\hline \multicolumn{3}{|l|}{ Original data } & \multicolumn{2}{|c|}{ Data in reverse order to make graph } & \multirow{2}{*}{$\begin{array}{l}\text { Graph from } \\
\text { G3: H43 }\end{array}$} \\
\hline Word-like & Count & Relevance & Word-like (count) & Relevance & \\
\hline Issues & 530 & $100 \%$ & Relationship (24) & $5 \%$ & \\
\hline University & 495 & $93 \%$ & Diagnosed (36) & $7 \%$ & \\
\hline Students & 494 & $93 \%$ & Environment (38) & $7 \%$ & \\
\hline Mental & 489 & $92 \%$ & Lack (40) & $8 \%$ & \\
\hline Anxiety & 263 & $50 \%$ & Assessment (42) & $8 \%$ & \\
\hline Stress & 235 & $44 \%$ & Doing (43) & $8 \%$ & \\
\hline Feel & 212 & $40 \%$ & Need (46) & $9 \%$ & \\
\hline People & 203 & $38 \%$ & Things (47) & $9 \%$ & \\
\hline Time & 186 & $35 \%$ & Others (47) & $9 \%$ & \\
\hline Depression & 171 & $32 \%$ & Semester (49) & $9 \%$ & \\
\hline Support & 163 & $31 \%$ & Services (49) & $9 \%$ & \\
\hline Friends & 156 & $29 \%$ & Stressed (50) & $9 \%$ & \\
\hline Cause & 144 & $27 \%$ & Degree (56) & $11 \%$ & \\
\hline Work & 140 & $26 \%$ & Experienced (57) & $11 \%$ & \\
\hline Pressure & 119 & $22 \%$ & Academic (58) & $11 \%$ & \\
\hline Study & 113 & $21 \%$ & During (59) & $11 \%$ & \\
\hline Life & 113 & $21 \%$ & School (6I) & $12 \%$ & \\
\hline Experience & 110 & $21 \%$ & Believe (66) & $12 \%$ & \\
\hline Due & 103 & $19 \%$ & Family (75) & $14 \%$ & \\
\hline Problems & 97 & $18 \%$ & Social (78) & $15 \%$ & \\
\hline Social & 78 & $15 \%$ & Problems (97) & $18 \%$ & \\
\hline Family & 75 & $14 \%$ & Due (103) & $19 \%$ & \\
\hline Believe & 66 & $12 \%$ & Experience (II0) & $21 \%$ & \\
\hline School & 61 & $12 \%$ & Life $(1 \mid 3)$ & $21 \%$ & \\
\hline During & 59 & $11 \%$ & Study (II3) & $21 \%$ & \\
\hline Academic & 58 & $11 \%$ & Pressure (I19) & $22 \%$ & \\
\hline Experienced & 57 & $11 \%$ & Work (140) & $26 \%$ & \\
\hline Degree & 56 & $11 \%$ & Cause (144) & $27 \%$ & \\
\hline Stressed & 50 & $9 \%$ & Friends (156) & $29 \%$ & \\
\hline Services & 49 & $9 \%$ & Support (163) & $31 \%$ & \\
\hline Semester & 49 & $9 \%$ & Depression (I7I) & $32 \%$ & \\
\hline Others & 47 & $9 \%$ & Time (I86) & $35 \%$ & \\
\hline Things & 47 & $9 \%$ & People (203) & $38 \%$ & \\
\hline Need & 46 & $9 \%$ & Feel $(212)$ & $40 \%$ & \\
\hline Doing & 43 & $8 \%$ & Stress (235) & $44 \%$ & \\
\hline Assessment & 42 & $8 \%$ & Anxiety (263) & $50 \%$ & \\
\hline Lack & 40 & $8 \%$ & Mental (489) & $92 \%$ & \\
\hline Environment & 38 & $7 \%$ & Students (494) & $93 \%$ & \\
\hline Diagnosed & 36 & $7 \%$ & University (495) & $93 \%$ & \\
\hline Relationship & 24 & $5 \%$ & Issues (530) & $100 \%$ & \\
\hline
\end{tabular}

The data identified most strongly concepts associated with (1) issues, (2) time and (3) people. Related concepts to the main concept of issues included students, cause, stress, depression, anxiety, 


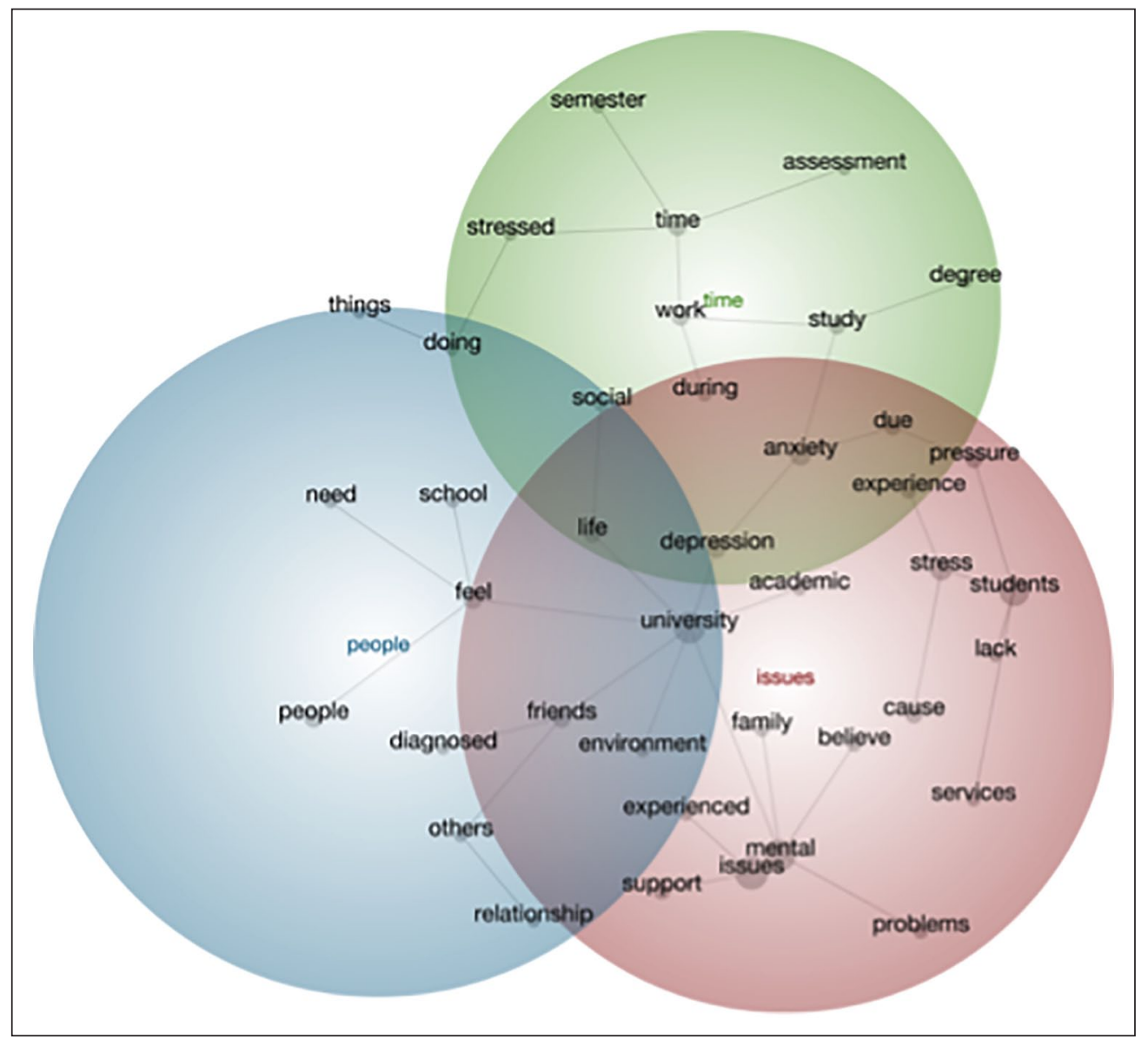

Figure I. Ranked concept map.

mental, diagnosed, problems and environment. Related concepts to the concept of time included semester, degree, study, school, university, academic, experience, work and pressure. Linked to the concept of people were concepts such as friends, family, school and relationships.

\section{Conceptual framework - themes and domains}

In line with Creswell's (2008) visual model for coding in qualitative research, a process of segmenting and labelling text to form descriptions and broad themes was undertaken supported by the Leximancer findings. Ranked concepts (issues, time and people) and associated domains (personal, community, home and university) were brought together to form a conceptual framework (Figure 2). Data analysis allowed for the ranking of participants' comments based on the number of common statements and the 'hits' recorded for each phrase or term, thus allowing thematic categorisation and concept development to build the conceptual framework. 


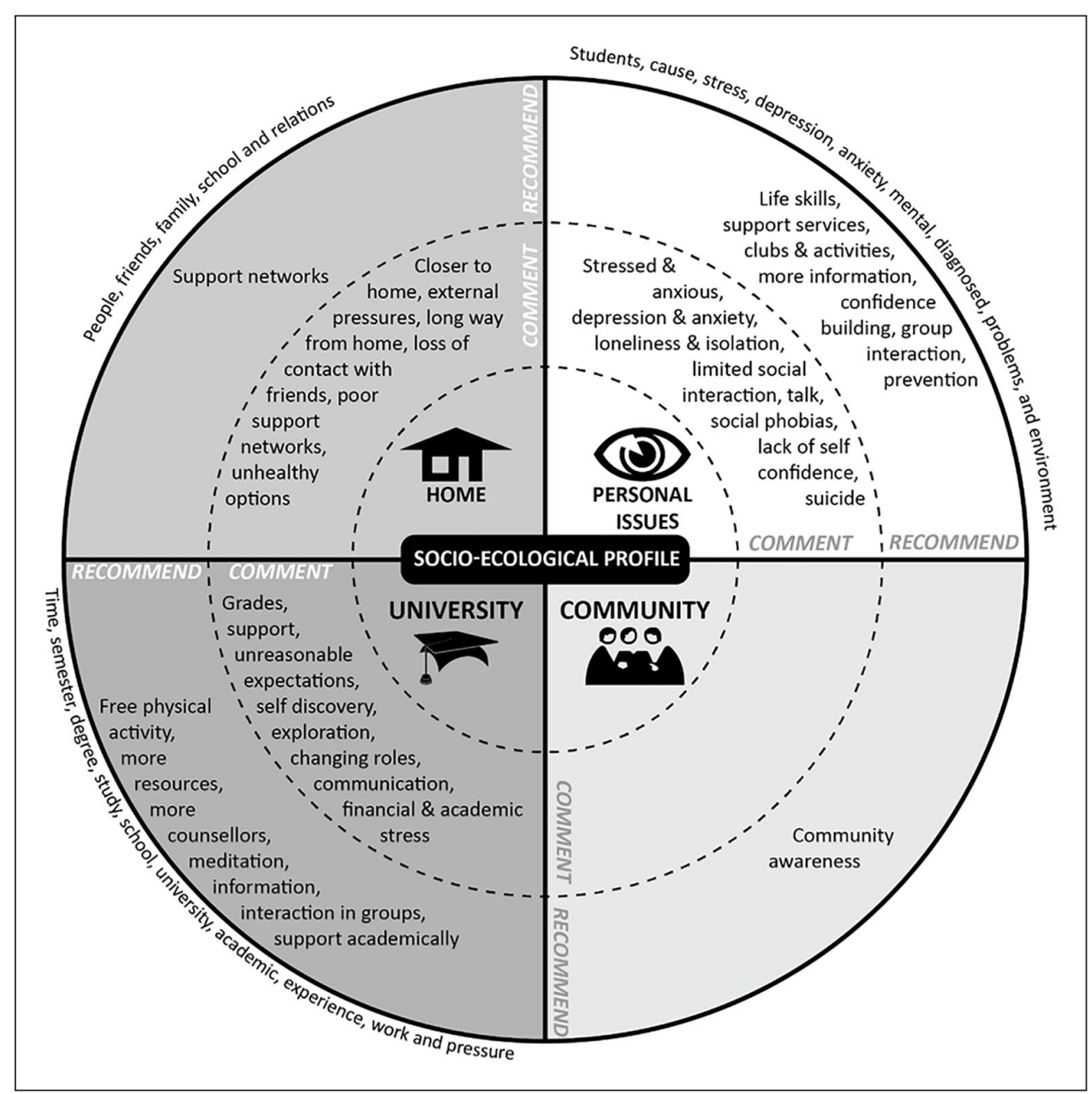

Figure 2. Conceptual framework - thematic categories and concepts.

\section{Findings and discussion}

In summary, the three main themes participants identified as associated with their lived and witnessed experiences of mental health issues were (1) personal - stressed and anxious; (2) home closer to home; and (3) university - grades. In relation to participants' recommendations for future intervention and development, the three main themes were (1) personal - life skills; (2) home support networks; and (3) university - free physical activity.

\section{Lived and/or witnessed experiences}

Personal. The most prominent theme across all domains, but especially in the personal domain indicated that students were 'stressed and anxious'. A typical statement came from participant \# 670 as follows:

Typically, very stressed and anxious about how to balance my life, my work and university commitments. Heaps and heaps and heaps and heaps of depression and anxiety. 
Another quote that supports such findings was provided by participant \# 209:

Stress is constant, and anxiety is a massive issue. There is no end to this and it is a growing issue across the university. I feel no one sees me or will help me.

Findings from this study mirror previous similar research which has identified a growing number of Australia's university students (19.2\%) with serious mental health problems on campus and an increase in the number of students seeking counselling (Said et al., 2013). In particular, findings from this study reveal parallels with previous research $(n=6,479)$ by Stallman $(2010)$ who found that the majority of Australia's university students (83.9\%) reported elevated distress and anxiety levels, consistent with university students being a high-risk population for mental health issues and problems.

Elsewhere, Veness (2016) has posited that such poor, continuing mental health trends erode the society's creative, productive and economic potential and are predicted to be the direct cause of an estimated \$16 trillion lost from the world's economy in the next 20 years. Apart from economic loss, implications of students' mental health problems directly impact university faculty, staff and the wider institution (Fried, 2011). In Veness's (2016) view, 'Few Australian universities have made a significant commitment to improving their students' mental health, failing to acknowledge its innate connection with their teaching and research objectives' (p. 8).

Home. The theme 'closer to home' was identified by many participants as a second main theme. It was closely linked to support and 'support networks'. Many students, commencing first-year university, experience negative impacts from leaving home for the first time. This theme emerged in statements such as,

My sister moved to university last semester and lived by herself a long way from home and her mental health was tampered with. (Participant \# 84)

Young, emerging adults, who are transitioning out of the family and familiar surroundings to attend university have been the focus of research for several years. A recent retrospective study of young people transitioning to adult life identified a number of factors that have a significant impact on their mental health status (Stallman, 2010). A significant number of young people who move away from their parents, family and friends to attend university experience anxiety and stress and thereby represent one of the most vulnerable groups in higher education settings (Fried, 2011). This experience was typified by one participant (\# 35) who stated,

I moved back home to be closer to my family and friends, I saw a psychologist to better understood anxiety and myself. I feel ashamed that I could not cope with being away from home, but it was such a big, fast change.

University. The theme of 'grades' recurred throughout the analysis across the university domain. It was closely associated with large academic workloads, examinations and academic pressure to achieve higher marks. One participant (\#47) indicated,

The university makes students feel that their grades mattered more than their mental health. The whole process is about getting results and not worrying about the students' wellbeing. It's very different than high school. I feel I am just a number.

The role of higher education as an instrument of change has long been acknowledged, with Stallman (2010) suggesting that universities achieve this by producing highly skilled graduates and 
economically motivated research outputs. Given the academic and economic downwards pressure to do so, it is perhaps not surprising that students often feel the pressure. By seeking to build a strong 'sense of coherence' in the learning environment and organisational culture, universities place themselves in a better position to promote health (Stallman, 2010), which in turn, plays a central part in enhancing or developing their students' sense of well-being (Veness, 2016).

While student services have an important role to play in supporting academic and emotional well-being, there is also evidence that social networks are key too, affecting a range of psychosocial factors important to well-being through the provision of a sense of felt social support, cohesion and sense of belonging. Together, these contribute to the 'collective efficacy' (informal support and collective action) and the 'cultural norms' of an institution (Dooris et al., 2017). In higher education settings, the importance and impact of social change cannot be underestimated - sometimes with negative and troublesome consequences. As participant \# 10 put it,

People in university are generally at a vulnerable stage in their lives re: self-discovery and exploration, exposure to new and exciting things, new and changing roles and relationships, changing future outlooks, and differing family situations along with the financial and academic stress that's involved with being a student.

\section{Recommendations for future intervention and development}

\section{Personal}

The theme of 'life skills' recurred throughout the analysis. One participant (\# 934) stated,

People put so much stress on academic achievement, life skills can be overlooked. Our education system, from primary school, needs to focus on life skills (interaction, knowing yourself) and not just grades and certain subjects. This way, we'll have more well-adjusted young adults that will be better able to cope with the pressure of uni and the process of growing up.

Despite clear evidence of mental health problems among university students, there has been minimal effort to introduce preventive and management treatment for mental health issues in higher education settings (Stallman, 2011). Given that, in Australia, mental disorders constitute the third largest source of disease burden after cancer and cardiovascular disease, and the largest source of disability burden (Begg et al., 2007), there is value in helping university health services provide students with effective evidence-based interventions. One such intervention strategy, as frequently recommended by participants, would be to offer some form of life skill straining to assist students navigate the challenges that present themselves throughout the emerging adult phase.

Personal health issues in the form of anxiety and loneliness are warning signs for the development of mental health problems among university students. Such indicators and findings from this study could form the basis for future intervention strategies concerning mental health in higher education settings. These might include building and promoting clear pathways to assist students with mental health problems link to university and community support. Comparative studies could also be undertaken to understand the impact of combining targeted interventions that address each of the domains, themes and concepts as highlighted in the conceptual framework (Figure 2).

\section{Home}

Support networks emerged as prominent in the home domain and the link between such networks and mental health is increasingly recognised (Katherine et al., 2006). 
One participant (\#390) voiced the importance of networks as follows:

Supportive networks established or activated in that individual's life, making sure there are people in their lives who can truly support and encourage them.

Fulfilling relationships with family, friends and significant others are fundamental to a meaningful and happy life (Myers, 2000). Close and supportive networks benefit the individual through better health outcomes, improved coping and increased life satisfaction, with numerous studies showing that being emotionally supported protects against physical illness and premature death (Berkman et al., 2000). In addition, social relationships have been found to affect mental health through their influence on individual stress, depression, anxiety and psychological well-being (Kawachi and Berkman, 2001).

\section{University}

The theme of free physical activity emerged in recommendations for the future, with many participants seeing participation in physical activity as an effective strategy for preventing and managing mental health issues. As one participant (\# 589) said,

I found that recently by increasing my physical activity [I joined the gym and now play a team sport], I was generally more relaxed and slept better and became much happier.

The World Health Organisation (2014) has argued that physically active youth are healthier, happier and more socially connected than those who have more sedentary lifestyles. However, despite comprehensive national health promotion campaigns and policy implementation, Australians, of all ages, are increasingly physically inactive with many undertaking far less than the recommended guidelines of daily physical activity (Active Healthy Kids Australia, 2014; Keegan et al., 2013). Australian youth are among those with the lowest physical activity levels leading to obesity and associated problems (Active Healthy Kids Australia, 2014).

In recent research, Paluska and Schwenk (2000) claims that, 'Although people with depression tend to be less physically active than non-depressed individuals, increased aerobic exercise/ strength training reduces depressive symptoms significantly' (p. 35). Research by Vella et al. (2015) supports such claims, suggesting,

Emotional wellbeing is one aspect of good mental health, and there is evidence to support the notion that emotional wellbeing supports sport participation and athletic performance, and vice versa. Sport participation appears to have an influence on one's psycho-social development, even from a very young age and particularly during fundamental (i.e. not elite) stages of sport development. (p. 1)

The literature suggests however that more rigorously controlled studies are needed to clarify the effects of physical activity on student mental health (Morgan et al., 2013). In their absence, the importance of exercise is not adequately understood or appreciated by patients and mental health professionals alike (Battaglia et al., 2016) and exercise remains an often-neglected intervention in mental health treatment and prevention (Binkowska-Bury and Januszewicz, 2010; Sharma et al., 2006).

In order to address these issues, access to sports and physical activity programmes should be made more affordable to all students; especially to students from lower socio-economic backgrounds. There is growing evidence that referral to a community sports club may provide an effective alternative to pharmaceutical treatment for some mental health disorders (Vella et al., 2015). However, as Morgan et al. (2013) suggest, 'There is limited research on the optimal type and dose of exercise suitable for individuals with mental disorders' (p. 65). 


\section{Conclusion}

Bronfenbrenner's (1994) socio-ecological model stresses the connectedness underpinning different social domains as they impact health experiences, behaviours and practices. An individual's immediate physical and social environment (their microsystem), as well as interactions between this system and the meso, exo and macro systems, has consequences for well-being and health. Thus, the university setting is an important one in which to intervene to promote students' health. A dedicated and strategic commitment to embedding university policies aimed at heightening students' health and well-being sustainably (Vella et al., 2015) provides the perfect springboard for co-ordinated action to develop college campuses which can be considered health promoting or salutogenic (Dooris et al., 2017).

This study has outlined a conceptual framework for the promotion of student mental health that emerged from participants' own commentaries as categorised across four specific domains. The framework identifies some of the key factors that influence perceptions, feelings, beliefs and behaviours relevant to student mental health. By taking into account the connections between four domains (personal, home, university and community), future interventions are more likely to be successful. Findings from this research provide a map of the situation as it currently stands in five universities, and identified appropriate ways to proceed in the future. They provide impetus to Australia's university sector, community health services, sports organisations and the fitness industry in developing and implementing future health-promoting strategies and campaigns. They also identify practical ways of substantially improving intervention programmes.

Potentially effective strategies could include greater recognition of the home and of prior and current social networks, the provision of alternative ways to meet degree requirements, the provision of extra time to complete assignments and greater flexibility in course load/timing. Heightened collaboration between academics, student services, students with mental health issues and community mental health services is also important. While no single set of factors predicts success when supporting university students with emotional problems, if universities embrace a philosophy which makes inclusion and support paramount, instigate a raft of support services available to students, and provide education and training on student mental health issues to a wide range of academics, there is a high likelihood that emotionally vulnerable students will feel supported so as to break the negative cycle that is typically associated with poor mental health.

\section{Funding}

The author(s) received no financial support for the research, authorship and/or publication of this article.

\section{ORCID iD}

Wayne Usher (iD https://orcid.org/0000-0003-4227-7174

\section{References}

Active Healthy Kids Australia (2014) Is Sport Enough? The 2014 Active Healthy Kids Australia Report Card on Physical Activity for Children and Young People. Adelaide, SA, Australia: Active Healthy Kids Australia.

Australian Institute of Health and Welfare (AIHW) (2012) Australia's health 2012. Available at: http://www. aihw.gov.au/publication-detail/?id=10737422172

Battaglia G, Bellafiore M, Alesi M, et al. (2016) Effects of an adapted physical activity program on psychophysical health in elderly women. Clinical Interventions and Aging 11: 1009-1015. 
Begg S, Vos T, Barker B, et al. (2007) The Burden of Disease and Injury in Australia 2003. Canberra, ACT, Australia: Australian Institute of Health and Welfare. Available at: http://www.aihw.gov.au/publicationdetail/?id=10737422172

Berkman LF, Glass T, Brissette I, et al. (2000) From social integration to health: Durkheim in the new millennium. Social Science and Medicine 51: 843-857.

Binkowska-Bury M and Januszewicz P (2010) Sense of coherence and health-related behaviour among University students - A questionnaire survey. Journal of Public Health 18(3): 145-150.

Braun V and Clarke V (2006) Using thematic analysis in psychology. Qualitative Research in Psychology 3(2): 77-101.

Bronfenbrenner U (1994) Ecological models of human development. In: Husen T and Postlethwaite N (eds) International Encyclopedia of Education. Oxford: Elsevier, pp. 1643-1647.

Bronfenbrenner U (1999) Measuring Environment across the Life Span: Emerging Methods and Concepts (ed Friedman SL and Wachs TD). Washington, DC: American Psychological Association Press.

Creswell J (2008) Educational Research - Planning, Conducting, and Evaluating Quantitative and Qualitative Research (3rd ed.). Upper Saddle River, NJ: Pearson Education.

Denzin N and Lincoln Y (1998) The Landscape of Qualitative Research - Theories and Issues. Thousand Oaks, CA: SAGE.

Dooris M, Doherty S and Orme J (2017) The application of salutogenesis in universities. In: Mittelmark M, Sagy S, Eriksson M, et al. (eds) The Handbook of Salutogenesis. Cham: Springer, pp. 35-46.

England KVL (1994) Getting personal: Reflexivity, positionality, and feminist research. The Professional Geographer 46(1): 80-89.

Fried L (2011) Teaching teachers about emotion regulation in the classroom. Australian Journal of Teacher Education 36(3): 117-127.

Imel S, Kerka S and Wonacott M (2002) Qualitative research in adult, career, and career-technical education. Available at: http://www.calpro-online.org/eric/docs/pfile05.htm

Katherine L, Fiori C, Antonucci S, et al. (2006) Social network typologies and mental health among older adults. The Journals of Gerontology, Series B 61(1): P25-P32.

Kawachi I and Berkman LF (2001) Social ties and mental health. Journal of Urban Health 78: 458.

Keegan R, Keegan S, Daley S, et al. (2013) Getting Australia moving: Establishing a physically literate and active nation (Game plan). Available at: http://www.canberra.edu.au/researchrepository/file/50f8c79c2aca-a83f-aee8-254288c36220/1/full_text_final.pdf

Modernes K (2007) Understanding the 'mixed ability' program in Catholic secondary schools in Mauritius: Perceptions of educators for best practice in the middle years of schooling. Available at: http://library. acu.edu.au/digitaltheses/public/adt-acuvp181.20112008/02whole.pdf

Morgan A, Alexandra G, Parker P, et al. (2013) Exercise and mental health: An exercise and sports science Australia commissioned review. Journal of Exercise Physiology 16(4): 64-70.

Myers DG (2000) The funds, friends, and faith of happy people. American Psychologist 55: 56-67.

Paluska S and Schwenk T (2000) Physical activity and mental health: Current concepts. Sports Medicine 29(3): 167-180.

Pullman AW, Masters RC, Zalot LC, et al. (2009) Effect of the transition from high school to University on anthropometric and lifestyle variables in males. Applied Physiology Nutrition Metabolism 34(2): $162-171$.

Said D, Kypri K and Bowman J (2013) Risk factors for mental disorder among university students in Australia: Findings from a web-based cross-sectional survey. Social Psychiatry and Psychiatric Epidemiology 48(6): 935-944.

Sharma A, Madaan V and Petty FD (2006) Exercise for mental health. Primary Care Companion to the Journal of Clinical Psychiatry 8(2): 106.

Stallman H (2010) Psychological distress in university students: A comparison with general population data. Australian Psychologist 45(4): 249-257.

Stallman H (2011) Mental illness running high among uni students. The World Today. Retrieved from: http:// www.abc.net.au/news/2010-11-23/mental-illness-running-high-among-uni-students/2348772 
Vella S, Cliff DP, Magee C, et al. (2015) Associations between sports participation and psychological difficulties during childhood. Journal of Science and Medicine in Sport 18(3): 304-309.

Veness B (2016) The wicked problem of university student mental health. Report to the Winston Churchill Memorial Trust, Sydney, NSW, Australia, January. Available at: https://www.churchilltrust.com.au/ media/fellows/Veness_B_2013_The_wicked_problem_of_university_student_mental_health.pdf

World Health Organisation (2014) Global strategy on diet, physical activity and health. Available at: http:// www.who.int/dietphysicalactivity/en/ 